\title{
Unintentional Vandalism: Unskilled tree pruning practices in tree management
}

\author{
Helmi Hamzah¹, Noriah Othman², Norainiratna Badrulhisham³, Lina Karlinasari \\ ${ }^{1}$ Centre of Studies for Landscape Architecture, Department of Built Environment Studies and Technology, \\ Universiti Teknologi MARA Perak Branch, Seri Iskandar Campus, Malaysia \\ ${ }^{2}$ Centre of Studies for Landscape Architecture, Faculty of Architecture, Planning and Surveying, \\ Universiti Teknologi MARA Selangor Branch, Puncak Alam Campus, Malaysia \\ 3 Institute of Graduate Studies, University Teknologi MARA, Shah Alam, Malaysia \\ ${ }_{4}^{4}$ Department of Forest Products, Faculty of Forestry and Environment, IPB University, Indonesia
}

helmi.treev@gmail.com, noriaho@yahoo.com, onie_ratna@yahoo.com Tel: +6019 2806604

\begin{abstract}
Urban trees are exposed to "unintentional vandalism" during poorly skilled pruning practices that can lead to tree structure damage. This causes harmful consequences that affect tree performance in terms of the ecosystem services they contribute. This study aims to explore the relationship between unintentional tree vandalism and poorly skilled pruning practices in tree maintenance by analysing qualitative and quantitative data from tree workers contracted by selected Malaysian local authorities and tree care experts. The results showed that insufficient tree pruning knowledge leads to unintentional vandalism in tree pruning practices.
\end{abstract}

Keywords: Tree management; unskilled tree pruning; unintentional tree vandalism; urban tree

eISSN: 2398-4287@ 2021. The Authors. Published for AMER ABRA cE-Bs by e-International Publishing House, Ltd., UK. This is an open access article under the CC BYNC-ND license (http://creativecommons.org/licenses/by-nc-nd/4.0). Peer-review under responsibility of AMER (Association of Malaysian Environment-Behaviour Researchers), ABRA (Association of Behavioural Researchers on Asians/Africans/Arabians) and cE-Bs (Centre for Environment-Behaviour Studies), Faculty of Architecture, Planning \& Surveying, Universiti Teknologi MARA, Malaysia.

DOI: https://doi.org/10.21834/ebpj.v6i16.2633

\subsection{Introduction}

Urban trees are a source of ecosystem services that have a significant impact on the quality of human life. Therefore, urban trees need proper care to ensure their continued overall health and safety; thus, they need to be professionally inspected and constantly maintained. Most people believe that biotic factors, such as insects and diseases, are the primary cause of the decline and death of trees in the landscape but in most cases, it is human activities (abiotic factors) which cause most problems that trees experience (Ordóñez et al., 2018). One important element in the care of urban trees is pruning. The primary purposes of pruning are to remove dead, damaged or diseased branches, to selectively eliminate crowded branches or stems, to correct structural problems and to control the shape of the tree. If done properly, pruning will help to maintain the health and aesthetic values of the trees but if done incorrectly, it can cause irreversible damage which may result in disservices of trees. How can we relate the act of pruning with vandalism? It is well known that the term vandalism refers to incidents that will lead to the ability to destroy, which results in the loss of individual and public property. Long \& Burke (2015) opined that vandalism is the destruction of any public or private property without the consent of the person. In a

eISSN: 2398-4287@ 2021. The Authors. Published for AMER ABRA cE-Bs by e-International Publishing House, Ltd., UK. This is an open access article under the CC BYNC-ND license (http://creativecommons.org/licenses/by-nc-nd/4.0). Peer-review under responsibility of AMER (Association of Malaysian Environment-Behaviour Researchers), ABRA (Association of Behavioural Researchers on Asians/Africans/Arabians) and CE-Bs (Centre for Environment-Behaviour Studies), Faculty of Architecture, Planning \& Surveying, Universiti Teknologi MARA, Malaysia.

DOI: https://doi.org/10.21834/ebpj.v6i16.2633 
broader sense, Yavuz \& Kuloğlu (2010) stated that vandalism is an action with social, psychological, spatial and economic aspects that have negative impacts on the environment. Based on Yavuz \& Kuloğlu (2010), it can be said that the act of incorrect pruning activities which could have a negative impact on trees and eventually on the environment is considered vandalism. The act of pruning and making mistakes due to a lack of knowledge and skill is termed "unintentional vandalism". "Unintentional vandalism" has contributed to many possible failures in the urban tree management field, and has the potential to cause tree disservices factors (Hamzah et al., 2020). Song et al. (2018), in their reviews on the economic benefits and costs of trees, emphasised that maintenance will determine the services and disservices of the trees. Thus, improper pruning could cause disservices of urban trees which affect the environment. Furthermore, several studies have claimed that unintentional acts of vandalism, which can also be referred to as accidental, can happen during tree maintenance work (Fickri \& Siregar, 2018; Morgenroth et al., 2015). Improper pruning could cause more damage due to longer cut recovery time and in the worst cases could cause the slow death of a tree (refer Fig. 1). Although previous studies have demonstrated the effect of vandalism on tree properties (Hamzah et al., 2019; Morgenroth et al., 2015), less attention has been given to the failure of tree pruning work in Malaysia. While existing studies have reported improper pruning work (Badrulhisham \& Othman, 2020; Fickri \& Siregar, 2018), the relationship between unintentional tree vandalism and poorly skilled pruning practices in tree maintenance were not properly addressed. These raise questions about whether unskilled pruning practices will eventually initiate unintentional tree vandalism, and whether this is the main factor that relates to this occurrence. In light of this situation, an immediate investigation is needed.

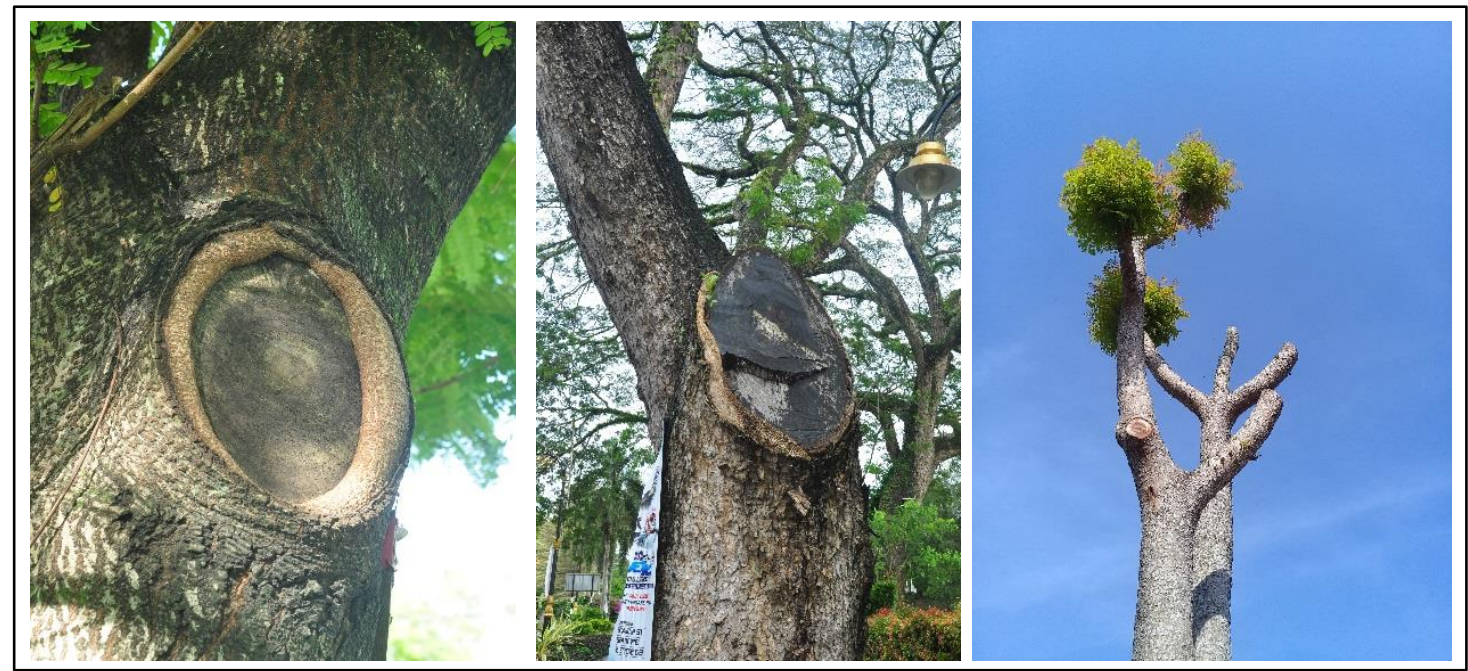

Fig. 1: Examples of tree pruning vandalism

(Source: Author)

The aim of this study is to investigate the relationship between skill in tree pruning practices and tree maintenance. The objectives are (1) to relate factors of unskilled tree pruning workers that can lead to unintentional tree vandalism, and (2) to identify factors behind an unknowledgeable tree pruning dimension among tree pruning workers. The rest of the paper is structured as follows: section two reviews the existing literature on the tree vandalism acts related to tree maintenance practices. Section three elaborates on the materials and methods. Section four describes the results and in-depth analysis, and is followed by a discussion of the results. Finally, section five presents the conclusions and recommendations for the future.

\subsection{Literature Review}

\subsection{Knowledge and skill in tree pruning}

Knowledge is the basis of the conduct or behaviour of an individual. Without knowledge, one cannot act upon any information or issues that arise. Dombrowski et al. (2013) explained that there are three kinds of knowledge: a) experiential knowledge; b) skills; and c) knowledge claims. Experiential knowledge is that which is gained through a direct connection with the environment through the sensory system and subsequently processed by the brain. Meanwhile, skills knowledge means the action-oriented and well-structured knowledge obtained by repeatedly performing a certain task and learning by doing it. The outcomes of best practice tree maintenance by tree workers are determined by the levels of their knowledge (Badrulhisham \& Othman, 2020). Formal elements (e.g., education level, tree maintenance training exposure) give promising knowledgeable outcomes to tree workers. Informal knowledge elements (e.g., working experience duration) show contributions to raising the quality of tree maintenance practices (Badrulhisham \& Othman, 2016). However, knowledge characteristics indicate the kinds of knowledge, skill, and ability needs that are placed on an individual in terms of what is done in the field (Bayona et al., 2020). The Person-Job Fit theory declares that workers with related characteristics to those present in the context exhibit more satisfaction and better performance (Leiter \& Bakker, 2010). Thus, knowledge characteristics indirectly influence job satisfaction and performance through their influence on work engagement. In other words, the special skills of tree care, including pruning, must be mastered to deliver high-calibre results. A study by Fickri \& Siregar (2018) on the quality of tree pruning cuts found 
that $93.91 \%$ of the trees in the Dramaga, Bogor campus area were not made properly, indicating that the workers still lacked pruning knowledge and skills. There are very few studies focusing specifically on the knowledge and skills of tree pruning. Major topics in previous pruning research addressed the morphological and physiological aspects of trees. When concerned with knowledge and urban trees, many researchers have reported on perception and preference studies of urban trees or urban forest, which are indirectly related to this study. Studies by Zhang et al. (2007) on public attitudes towards the urban tree and support for urban tree programmes in Alabama, USA, indicated that a public with more information and knowledge about the benefit of urban tree programmes and forestry services had a positive attitude and would be more likely to donate money to urban tree programmes. This finding especially referred to members of the public with higher education levels. Meanwhile, Gurung et al. (2012), who studied people's perceptions of urban forestry and institutional involvement in the Metropolitan City of Lalitpur in Nepal, found that respondents with higher levels of education have more knowledge about the ecosystem and perceived urban forest as an important element of sustainable landscapes. Kuhns \& Reiter (2009), whose study about the knowledge and attitudes of households towards utility pruning in six cities in the western United States, reported that individuals who are exposed to knowledge will have a positive attitude towards the acceptance of utility pruning. In addition, Almas \& Conway (2017) discovered that knowledge gained about native species increased people's positive actions to sustainable native tree species management.

\subsection{Ideology and practices}

The ideology and practices dimensions emerged as the principal dimensions underlying this dynamic field. Tree vandalism is considered a distinct type of social problem involving deliberate or accidental damage to urban trees. According to Hamzah et al. (2020b), tree vandalism incidents occur in both intentional and unintentional circumstances in the ideology and practices category. Humans intentionally modify or damage trees based on their ideological backgrounds, such as when stem curving and painting. On the other hand, a tree may be vandalised and damaged without any intention due to 'failure practices' in tree maintenance work (Fickri \& Siregar, 2018; Gilbertson \& Bradshaw, 1985; Hamzah et al., 2020b). This clearly defines unskilled maintenance workers performing improper tasks and thus influences low-quality workmanship within the tree maintenance programme. Different forms of the practical subject include improper tree pruning work (e.g., topping and flush cutting) and machinery contact (e.g., with a lawnmower). Several studies have shown the link between higher levels of failure practices and increased tree damage rates (Fickri \& Siregar, 2018; Morgenroth et al., 2015; Norainiratna et al., 2013; Sreetheran et al., 2011). From a different perspective, Dobbs et al. (2018) asserted that failure practices in tree maintenance as common mistreatment include improper branch tipping, the preferential removal of lower branches, excessive or frequent branch pruning, and aggressive crown reduction and thinning. Closely linked to ideology and practices is the outcome of the tree worker's knowledge.

In summary, the above reviews serve as a consideration of unintentional tree vandalism incidents in terms of unskilled workers' properties in tree maintenance practices. This review does not mean to imply that unskilled tree workers are related to the ideology and practices, and knowledge is of lesser concern in tackling the problems of tree vandalism. Instead, the view is taken that an understanding of the outcomes of destructive tree worker practices in tree maintenance work can at least build on a systematic appraisal of acts of tree vandalism. Fig. 2 illustrated the consideration of tree worker's properties for tree pruning practices.

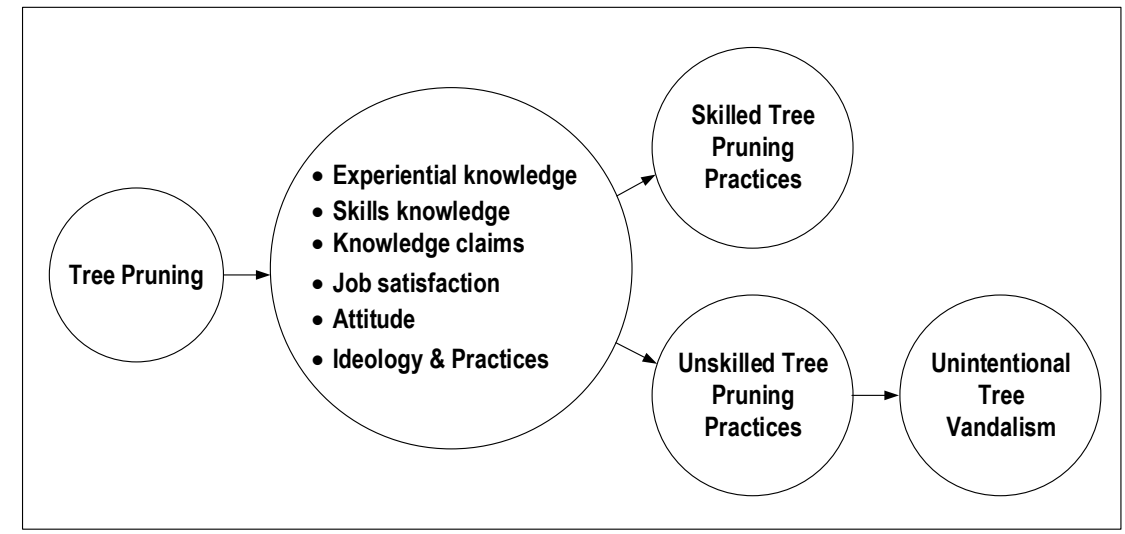

Fig. 2: Consideration of tree worker's properties for tree pruning practices (Source: Author's illustration)

\subsection{Methodology}

This study employed a mixed-method approach to cross-validate relationships between tree pruning practices and unintentional tree vandalism incident. Analysis was done on both the qualitative and quantitative data which was collected within a period of six months in 2019. There were two types of data collection techniques: first, an open-ended questionnaire survey, and second, a closed-ended questionnaire survey. 


\subsection{Open-ended questionnaire survey}

The questionnaires were distributed to tree care experts in Malaysia, known as certified arborists. The convenient sampling technique was used in this survey, with a total of 37 experts who agreed to participate in this study. The qualitative questionnaires were designed with a photos-elicitation method comprising four groups of images representing failures in tree pruning situations, and the experts needed to interpret the tree vandalism incidence. Qualitative data were extracted through a coding analysis using the NVivo 11 programme to identify an unintentional tree vandalism pattern in tree pruning practices (International Society of Arboriculture, 2011).

\subsection{Closed-ended questionnaire survey}

The next stage was a quantitative data collection administered as a closed-ended questionnaire survey conducted among four selected local authorities in the Klang Valley, and which specifically targeted tree workers. Tree workers are people who conduct various forms of tree maintenance, including tree pruning. Selection of the four local authorities was made on a voluntary basis. Although consent letters were sent to various local authorities in Klang Valley, only four responded and agreed to participate in this study. The selection of tree pruning workers as respondents from Kuala Lumpur City Hall (DBKL), Shah Alam City Council (MBSA), Subang Jaya City Council (MBSJ), and Petaling Jaya City Council (MBPJ) was based on a purposive sampling to gauge their knowledge and skill in tree pruning activities. A total of 205 workers participated in this study. The data was analysed using SPSS statistical 25 software. This approach allowed an assessment of the level of knowledge of tree workers about tree pruning work. 58 items of questions related to the understanding of tree pruning were designed to achieve the objective of the study.

The factors for unskilled tree pruning work that led to unintentional tree vandalism incidents were determined by a convergence triangulation approach within the qualitative and quantitative results. This study embraced the arboriculture field in response to cultural practices and their environmental relationship to urban tree care.

\subsection{Findings}

\subsection{Respondent profiles}

For the qualitative data collection, 37 tree care experts, all Malaysian certified arborists, participated in this study. Data on the respondents' profiles included their working sector and working experience as certified arborists. Fig. 3 presents the profiles of the experts who participated in the study. Out of 37 experts, 30 had more than five years of experience as certified arborists. Nineteen experts were involved with private tree care practitioners, while the rest were government servants.

For the quantitative data collection, a total of 205 respondents in this study worked with landscape contractors and were involved in the tree pruning work of Malaysian city councils. Fig. 4 shows the percentages of tree pruning workers in terms of their roles in the selected local authorities. The percentages represent their roles in tree pruning work according to their position, i.e., subordinate positions represented 55.6 per cent, supervisory roles represented 34.1 per cent, and managerial roles represented 10.2 per cent. It was essential to seek their level of understanding of tree pruning knowledge and pruning implementation because they were the group at the forefront, that is, directly engaged in the pruning activities.

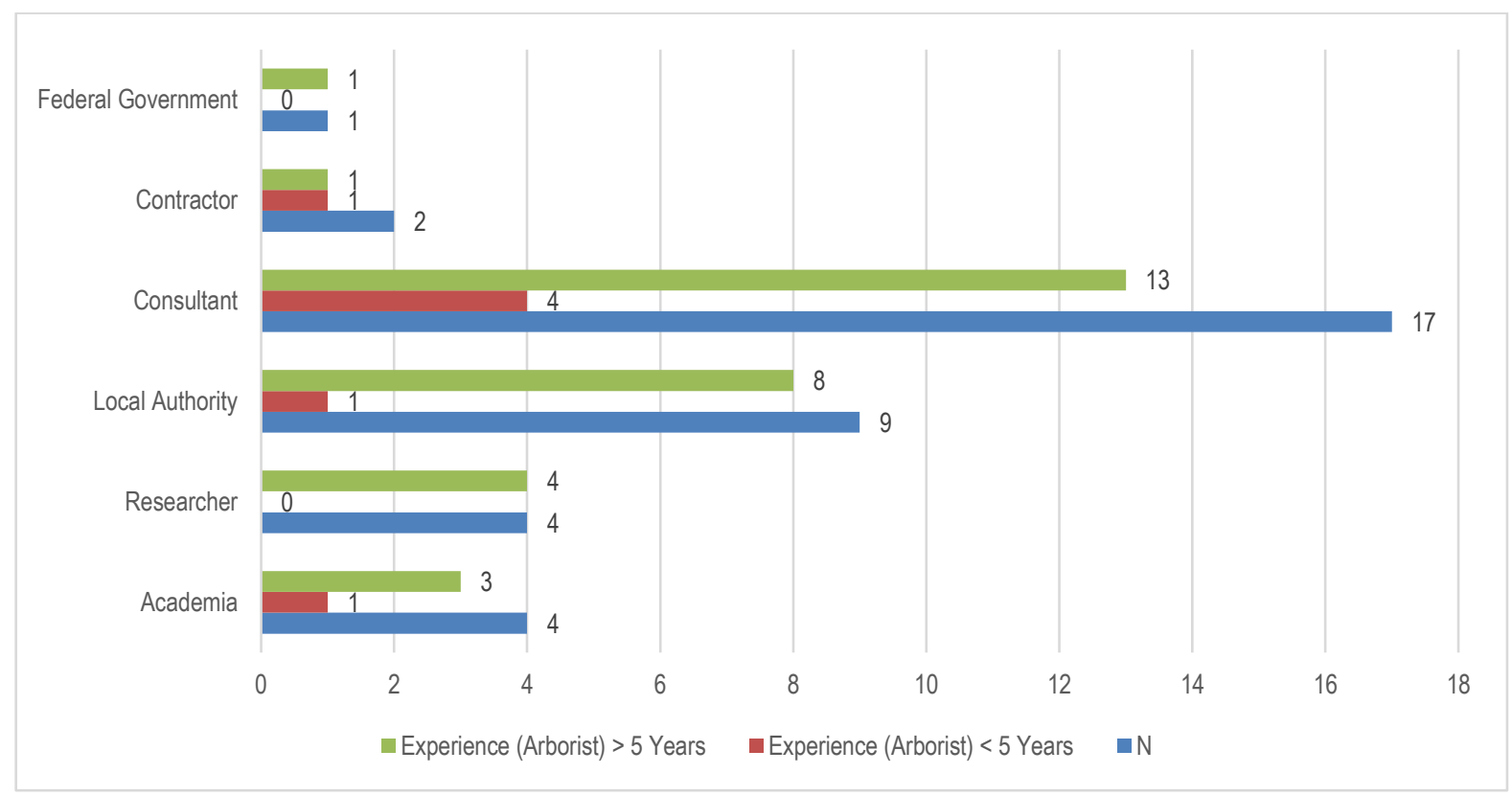

Fig. 3: Profiles of the tree care experts

(Source: Author) 


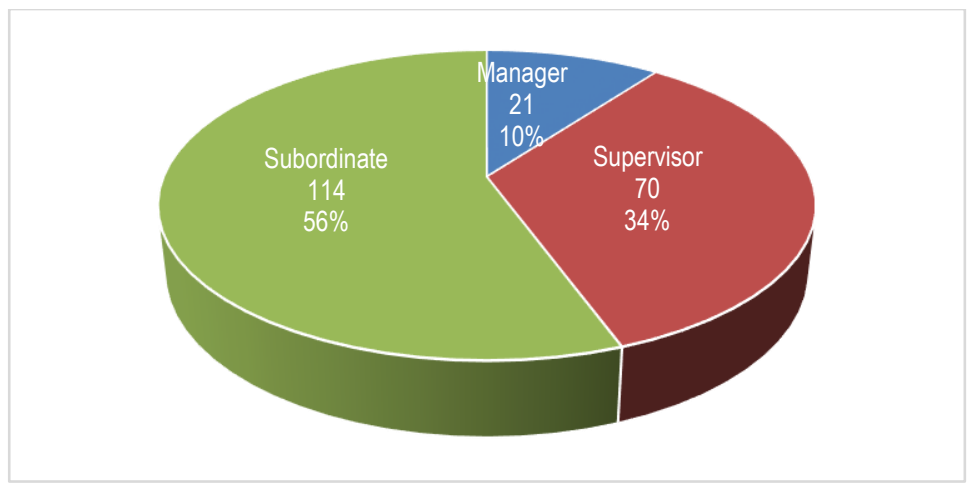

Fig. 4: Roles of the tree pruning workers

(Source: Author)

The second part of the data collection covered a demographic survey of the tree workers related to their educational background, working experience, and frequency of attending pruning courses. These attributes will be reflected in a worker's knowledge, skills and ability in tree pruning work. This study discovered that most tree pruning workers are poorly educated, with 57.6 per cent being SPM holders and below, which accounted for 118 people. Workers who were diploma holders and above made up 42.4 per cent (87 people), as shown in Table 1. Tree pruning workers with technical backgrounds play a major role in ensuring the tree pruning practices are implemented accordingly for sustaining urban trees in local authorities' areas.

\begin{tabular}{lcc}
\multicolumn{3}{c}{ Table 1. Profiles of the tree pruning workers } \\
\hline Attribute & Frequency & $\%$ \\
\hline Education background: & 118 & 57.6 \\
SPM and below & 87 & 42.4 \\
Diploma and above & & \\
Working experience: & 111 & 54.1 \\
< 5 Year & 94 & 45.9 \\
$>5$ Year & & \\
Attending pruning course: & 39 & 19.0 \\
Never & 33 & 16.1 \\
1 time & 90 & 43.9 \\
$2-3$ time & 43 & 21.0 \\
$>4$ time & (Source: Author) &
\end{tabular}

Most tree pruning workers involved in this survey had worked in tree pruning work for less than five years; this covered 54.1 per cent $(\mathrm{N}=111)$ of the total tree pruning worker respondents. This was followed by those that had been working in tree pruning work for more than five years, who made up 45.9 per cent $(\mathrm{N}=94)$. In addition, one of the last questions examined how frequently they had attended pruning courses. The most important skill workers must have in tree pruning work is knowledge of the appropriate pruning technique. 19.0 per cent of the tree pruning worker respondents had never attended pruning course, which came to 39 people. 16.1 per cent of the workers had been involved in a one-time pruning course. 43.9 per cent had been involved two to three times in pruning courses, and only 21.0 per cent had been more than four times.

\subsection{Tree pruning: Unintentional tree vandalism pattern}

An analysis of the qualitative data discovered three unintentional tree vandalism factors in the failure of tree pruning practices. Experts confirmed that the factors involved in the incidence of unintentional tree vandalism in pruning work are the wrong pruning technique, and careless and poor workmanship. Theoretically, these factors stem from unknowledgeable workers and result in unskilled practices. Thus, successful implementation of best pruning practice by the tree pruning workers is limited when there is the loophole of unskilled workers.

\subsection{Tree workers' pruning knowledge}

The tree pruning worker respondents with a very good level of knowledge about appropriate tree pruning implementation were less than five per cent of the total, that is, only 4.9 per cent $(\mathrm{N}=10)$ from 205 tree pruning workers. The majority, 69.3 per cent $(\mathrm{N}=142)$ of tree pruning worker respondents, were at the level of good tree pruning knowledge. Almost a quarter of respondents', 23.9 per cent ( $N=49$ ), had a moderate level and 2.0 per cent $(\mathrm{N}=4)$ had a low level of tree pruning knowledge. Over half the respondents, 52.6 per cent $(\mathrm{N}=108)$, were mistaken on the topping dimension. Other dimensions of which respondents had low pruning knowledge were pruning type, 46.6 per cent $(\mathrm{N}=96)$, and pruning cut, 30.3 per cent $(\mathrm{N}=62)$. The data obtained show that the majority of pruning worker respondents were unknowledgeable about tree pruning dimensions that lead to pruning failure practices. 


\subsection{Unskilled tree pruning workers in unintentional tree vandalism}

With reference to the tree care experts' and tree pruning workers' interpretation, the factors of unskilled tree pruning practices can be divided into two different categories. Category 1 covers wrong technique (low knowledge), and careless and poorer workmanship reflecting the quality of pruning work implemented. Meanwhile, category 2 covers workers' low educational status, lack of working experience and less pruning course exposure, which reflect the backgrounds of tree pruning workers. Thus, the convergence triangulation shows that unintentional tree vandalism in pruning work was confirmed as deriving from insufficient tree pruning knowledge. Fig.5 shows the significant factors of unskilled tree pruning workers in relation to unintentional tree vandalism incidents.

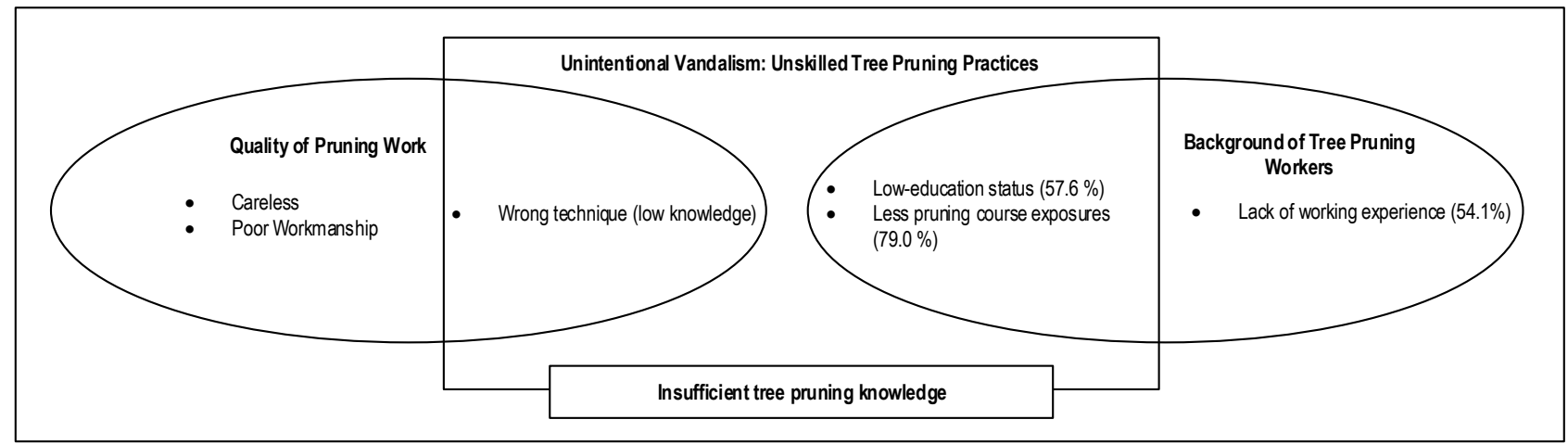

Fig. 5: Factors of unskilled tree pruning workers in relation to unintentional tree vandalism incidents

(Source: Author's illustration)

\subsection{Discussion}

This research has addressed the subject of failure in tree pruning practices by examining the knowledge of tree pruning workers (Badrulhisham \& Othman, 2020) and the quality of tree pruning cuts (Fickri \& Siregar, 2018). In extension to this, the study contributes to the field by exploring failure in tree pruning practices in terms of unintentional tree vandalism, which may be a concealed but crucial explanation for unskilled tree pruning practices in tree management. The outcomes of this study will assist and extend the understanding of tree worker practices concerning failure in tree pruning work. The findings of this study are consistent with the outcomes of previous research. A considerable number of studies obtained from the literature review consider unskilled practices a significant factor in tree damage (Fickri \& Siregar, 2018; Morgenroth et al., 2015). Based on a survey they conducted, Fickri \& Siregar (2018) concluded that most tree damage typically connects human factors with improper pruning. Similarly, this was supported by the findings of Morgenroth et al. (2015) in their study on a tree damaged due to improper maintenance practices. Aligned with this, in focusing on unintentional vandalism in unskilled tree pruning practices, this study shows that unintentional vandalism stems from the unskilled tree pruning factor, which is strongly associated with a tree pruning worker's knowledge of pruning techniques.

When discussing knowledge about pruning techniques, most tree pruning workers make mistakes unconsciously based on their understanding. Such mistakes include being misleading on the topping dimension, pruning types, and pruning cut, actions which have been implemented by most tree pruning workers who participated in this study; this has been verified by scholars (Badrulhisham \& Othman, 2016; Fickri \& Siregar, 2018; Sreetheran et al., 2011). Other mistakes stated by some scholars, including virus infestations which spread from pruning tools, an inappropriate size of branches pruned (Kennelly et al., 2016) and an incorrect pruning schedule (Darling et al., 2017; Koeser et al., 2016), fail to capture the attention of tree pruning workers. Thus, ignorance of tree pruning best practice is associated with insufficient pruning knowledge among tree pruning workers specified in this study. Therefore, the finding is consistent with Hamzah et al. (2020b), in that the features of an ideology and practices express failure practices which initiate unintentional tree vandalism in the form of mistakes, without any malicious intent but which are influenced by human error. Obviously, many tree vandalism incidents could have been caused by the errors of management practices. This classification as human error or wrongful and improper conduct motivated by indifference to the consequences of one's acts. Hence, changes in approach and in-depth improvements in pruning knowledge are crucial subjects for tree pruning workers.

\subsection{Conclusion \& Recommendations}

In conclusion, this study has established three key findings relating to the research objectives underpinning this study. Firstly, by gathering and analysing the qualitative data from the tree care experts, the study has expressed how unintentional tree vandalism stems in three ways from unskilled tree pruning work, that is, the wrong pruning technique, and careless and poor workmanship. Second, the study has identified three main factors behind an unknowledgeable tree pruning dimension among tree pruning workers. Analysing the tree pruning workers' data shows their low educational status, lack of working experience, and minimal exposure to pruning courses are among the main factors. Finally, the study has determined that insufficient tree pruning knowledge is a factor in unintentional vandalism in tree pruning practices through convergence triangulation approaches. The findings of the study provide necessary guidance to decisionmakers and tree managers in combatting tree vandalism issues as part of sustainable urban tree management. Theoretically, this study contributes to the body of knowledge in behavioural and vandalism studies by identifying specific factors behind unintentional 
vandalism in tree pruning practices. Moreover, the third and eleventh Sustainable Development Goals (SDGs) has focused on uplifting the quality of urban tree performances by effective urban tree management practices to provide a comfortable, satisfactory, quality and affordable environment for a liveable city. Aligns with that, the finding of this study can help improve the sustainability of quality of life, increase the functionality of urban trees for people living in a conducive environment. The respondents in this study are limited to tree care experts and tree pruning workers in Malaysia. This limits any generalisation to that particular local context. Future studies should investigate other regions in different countries to accommodate a generalisation within the global context. Even any generalization to other regions in different countries in the world should take into account the possible differences interpretations by the experts and tree workers in question. This is because all incidences of the tree vandalism act should be paralleled with the particular region's social, practices, and situational contexts.

\section{Acknowledgements}

The authors would like to acknowledge the cooperation of the respondents, both experts and tree pruning workers, who participated in the survey. The authors also wish to acknowledge the financial support provided by the Research Management Centre, Universiti Teknologi MARA through GIP GRANT, 600-IRMI 5/3/GIP (019/2019).

\section{Paper Contribution to Related Field of Study}

As stated earlier, very few studies have focused on the knowledge and skill of tree workers in pruning activities; therefore, the findings from this study demonstrate that contextual knowledge is an equally important factor in measuring the outcomes of in-role performance. In other words, the findings contributed to the field in a knowledgeable sense for policymakers and tree managers on the issue of "unintentional vandalism" to trees, which demands the collective endeavour of all parties to ensure the successful management of urban trees.

\section{References}

Almas, A. D., \& Conway, T. M. (2017). Residential knowledge of native tree species: A case study of residents in four Southern Ontario Municipalities. Environmental Management, 59(1), 21-33. https://doi.org/10.1007/s00267-016-0772-5

Badrulhisham, N., \& Othman, N. (2016). Knowledge in Tree Pruning for Sustainable Practices in Urban Setting: Improving Our Quality of Life. Procedia - Social and Behavioral Sciences, 234, 210-217. https://doi.org/10.1016/j.sbspro.2016.10.236

Badrulhisham, N., \& Othman, N. (2020). Assessing pruning knowledge towards effective tree maintenance: A case study of four Local Authorities in Malaysia. Environment-Behaviour Proceedings Journal, 5(13), 223-229. https://doi.org/10.21834/e-bpj.v5i13.2054

Bayona, J. A., Caballer, A., \& Peiró, J. M. (2020). The relationship between knowledge characteristics' fit and job satisfaction and job performance: The mediating role of work engagement. Sustainability (Switzerland), 12(2336). https://doi.org/10.3390/su12062336

Darling, L., Custic, M., Scott, L., \& Smith, C. S. (2017). Increasing the benefits from urban trees while minimizing costs: Lessons learned from the Chicago region trees initiative. Illinois Municipal Policy Journal, 2(1), 119-134.

Dobbs, C., Eleuterio, A. A., Amaya, J. D., Montoya, J., \& Kendal, D. (2018). The benefits of urban and peri-urban forestry. In A. Sarre (Ed.), Unasylva (Vol. 69, Issue 250, pp. 22-29). Food and Agriculture Organization of the United Nations.

Dombrowski, E., Rotenberg, L., \& Beck, M. (2013). Theory of knowledge. In University of Oxford (2013th ed.). Oxford University Press.

Fickri, S., \& Siregar, I. Z. (2018). Early identification of the quality of tree pruning cuts in a Bogor campus area. IOP Conference Series: Earth and Environmental Science, 203, 1-7. https://doi.org/10.1088/1755-1315/203/1/012024

Gilbertson, P., \& Bradshaw, A. D. (1985). Tree survival in cities: The extent and nature of the problem. Arboricultural Journal: The International Journal of Urban Forestry, 9(2), 131-142. https://doi.org/10.1080/03071375.1985.9746706

Gurung, A., Karki, R., Bista, R., \& Oh, S. E. (2012). Peoples' perception towards urban forestry and institutional involvement in metropolitan cities: A survey of Lalitpur City in Nepal. Small-Scale Forestry, 11(2), 193-205. https://doi.org/10.1007/s11842-011-9175-x

Hamzah, H., Othman, N., \& Hussain, N. H. M. (2019). The Tree Vandalism Model (TVM): Quantifying Urban Tree Vandalism Status. J1st International Conference on Green Technology and Sustainable Development (GTSD 2019), 24.

Hamzah, H., Othman, N., \& Mohd Hussain, N. H. (2020a). Addressing public dissatisfaction on urban tree management: A way to enhance landscape quality. International Journal of Advanced and Applied Sciences, 7(2), 15-19. https://doi.org/10.21833/ijaas.2020.02.003

Hamzah, H., Othman, N., \& Mohd Hussain, N. H. (2020b). Setting the criteria for urban tree vandalism assessment. Planning Malaysia, 18(4), 12-32. https://doi.org/10.21837/pm.v18i14.815

International Society of Arboriculture. (2011). Why hire an arborist. Consumer Information Program, 1-2.

Kennelly, M. M., Cloyd, R. A., O'Mara, J., \& Griffin, J. J. (2016). Tree and shrub problems in Kansas: Diseases, insects, and environmental stresses. Kansas State 
University.

Koeser, A. K., Vogt, J., Hauer, R. J., Northrop, R. J., \& Peterson, W. (2016). The cost of not maintaining trees: Findings and recommendations from an International Symposium and Summit. Arboriculture \& Urban Forestry, 42(6), 377-388. https://urbanforestry.indiana.edu/publications/Costnotmaintainingtreesp377-388.pdf

Kuhns, M. R., \& Reiter, D. K. (2009). Tree care and topping beliefs, knowledge, and practices in six western U.S. cities. Arboriculture and Urban Forestry, 35(3),122-128.

Leiter, M. P., \& Bakker, A. B. (2010). Work engagement: Introduction. In A. B. Bakker \& M. P. Leiter (Eds.), Work engagement: A handbook of essential theory and research (pp. 1-9). Psychology Press.

Long, M., \& Burke, R. H. (2015). Vandalism and anti-social behaviour. In P. Davies, P. Francis, \& T. Wyatt (Eds.), Critical Criminological Perspectives. Palgrave Macmillan. https://doi.org/10.1057/9781137519269

Morgenroth, J., Santos, B., \& Cadwallader, B. (2015). Conflicts between landscape trees and lawn maintenance equipment - The first look at an urban epidemic. Urban Forestry and Urban Greening, 14, 1054-1058. https://doi.org/10.1016/j.ufug.2015.10.002

Norainiratna, B., Manohar, M., \& Roslan, M. (2013). Health of trees in Titiwangsa recreational park, Kuala Lumpur, Malaysia. Journal of Sustainability Science and Management, 8(2), 191-196.

Ordóñez, C., Sabetski, V., Millward, A. A., Steenberg, J. W. N., Grant, A., \& Urban, J. (2018). The influence of abiotic factors on street tree condition and mortality in a commercial-retail streetscape. Journal of Arboriculture \& Urban Forestry, 44(3), 133-145.

Song, X. P., Tan, P. Y., Edwards, P., \& Richards, D. (2018). The economic benefits and costs of trees in urban forest stewardship: A systematic review. Urban Forestry and Urban Greening, 29, 162-170. https://doi.org/10.1016/j.ufug.2017.11.017

Sreetheran, M., Adnan, M., \& Khairil Azuar, A. K. (2011). Street tree inventory and tree risk assessment of selected major roads in Kuala Lumpur, Malaysia. Arboriculture and Urban Forestry, 37(5), 226-235.

Yavuz, A., \& Kuloǧlu, N. (2010). An experimental study on vandalism: Trabzon parks. Scientific Research and Essays, 5(17), $2463-2471$.

Zhang, Y., Hussain, A., Deng, J., \& Letson, N. (2007). Public attitudes toward urban trees and supporting urban tree programs. Environment and Behavior, 39(6), 797814. https://doi.org/10.1177/0013916506292326 